\title{
Study on Inheritance of Potato virus X Resistance in Capsicum annuum
}

\author{
Jinxia Shi ${ }^{1}$, Doil Choi ${ }^{1,2}$, Byung-Dong Kim ${ }^{1,2}$ and Byoung-Cheorl Kang ${ }^{1,2 *}$ \\ ${ }^{1}$ Department of Plant Science, Seoul National University Seoul 151-921, Korea \\ ${ }^{2}$ Plant Genomics and Breeding Institute, Seoul National University, Seoul 151-921, Korea \\ (Received on August 12, 2008; Accepted on November 6, 2008)
}

\begin{abstract}
Potato virus $X(\mathrm{PVX})$ resistance in potato is one of the best-characterized resistance models, however little is known in pepper. To evaluate the resistance to PVX in Capsicum annuum, a total of eleven pepper accessions were used for resistance screening against two PVX strains, USA and UK3. None of them were resistant against strain UK3, whereas four resistant genotypes were found against strain USA, three of which were further characterized. Two unlinked dominant genes were identified for both genotypes Bukang and Perennial; resistance in the genotype CV3 seemed to be conferred by two complementary dominant genes. These results demonstrated that the resistance to PVX in $C$. annuum is different from that in potato. This is the first report on genetic analysis of PVX resistance in $C$. annuum.
\end{abstract}

Keywords : Capsicum annuum, inheritance, Potato virus $X$, resistance

Potato virus $X$ (PVX), a flexuous rod-shaped virus containing a $6.4 \mathrm{~kb}$ plus-stranded RNA genome, is the type member of the potexviruses (Park et al., 2006). Firstly reported in potato (Solanum tuberosum) by Smith in the U.K in 1931 (Markham, 1977), PVX causes significant damages in many economically important crops including potato, tobacco, and pepper. The virus can be easily transmitted by mechanical inoculation and contact between plants in nature. Different PVX strains induce quite different symptoms on various hosts. For instance, some PVX strains show symptomless while others induce necrotic streaks in Solanum tuberosum; mild mosaic mottling, distortion of leaves and plant stunting symptoms are observed in Brassica rapa (http://image.fs.uidaho.edu/ vide/refs.htm).

PVX and its interaction with resistance genes have been very well characterized in potato (Solomon-Blackburn et al., 2001). Two types of resistance response have been identified in potato: hypersensitive resistance (HR) and

\footnotetext{
*Corresponding author.

Phone) +82-2-880-4563, FAX) +82-2-873-2056

E-mail)bk54@snu.ac.kr
}

extreme resistance (ER) (Cockerham, 1970). It has been known that HR is associated with prevention of virus movement (Malcuit et al., 1999) whereas ER acts on inhibition of virus accumulation (Kohm et al., 1993). Both types of resistance genes are inherited in a monogenic dominant fashion (Solomon-Blackburn et al., 2001). $N x$ and $\mathrm{Nb}$, related to $\mathrm{HR}$, are located on the long arm of chromosome IX (Tommiska et al., 1998) and in the middle of chromosome V, respectively (Marano et al., 2002). Two ER type $R x$ genes, $R x 1$ and $R x 2$, have been cloned (Bendahmane et al., 1999; Moffett et al., 2002) and mapped to chromosome XII and V, respectively (Ritter et al., 1991; Bendahmane et al., 1997).

Two kinds of methods have been used to classify PVX strains primarily based on their ability to overcome resistance genes. Cockerham (1954) divided PVX strains into four groups according to their compatibility with two dominant genes, $N x$ and $N b$ (Cockerham 1954; Kavanagh et al., 1992). The group 1 strain cannot infect plants having either $N x$ or $N b$. The group 2 strains can only infects plants with $N x$, while the group 3 can infect plants with $N b$. And the group 4 contains the widest host range that can induce systemic infection in plants containing $N x$ and $N b$ genes. But Rx1 and Rx2 confer resistance to all four groups of virus. The second method classifies PVX strains into two group, designated as type $\mathrm{X}$ and $\mathrm{B}$, by the coat protein (CP) amino acid identity and the avirulence on potato genotypes carrying the $N x$ resistance gene (Santa et al., 1995). There are 14 amino acid differences between type $\mathrm{X}$ and $\mathrm{B}$. The type B coat proteins are capable of overcoming the $N x$ resistance. In fact, most strains of group 1 and 3 are included into type $X$ and group 2 and 4 are into type B. Korean PVX strains, such as PVX-KR, PVX-KO1 and PVX-KO2, have been isolated previously. PVX-KO1 and $\mathrm{PVX}-\mathrm{KO} 2$ have been assigned to the type $\mathrm{X}$ and no classification analysis of PVX-KR has been performed, but this strains has very high homolog with PVX-KO1 and PVX-KO2 (Jung et al., 2000).

Although there have been many studies on PVX resistance in potato, little is known for PVX resistance in pepper which is one of the most importance fruit vegetable crops in Korea. Although several pepper accessions showing resis- 
tance to PVX have been identified, the study had been done twenty years ago and most of the identified resistant cultivars are not publically available (Green \& Kim 1994). The objectives of this study are to evaluate the resistance to two PVX strains in $C$. annuum and to analyze the inheritance of the resistance.

\section{Materials and Methods}

Plant materials and genetic populations. Eleven pepper (C. annuum) genotypes were used for resistant screening against PVX (listed in Table 1). Pepper seeds were germinated in a humid plastic petri dish in a $30^{\circ} \mathrm{C}$ incubator after sterilization. One week later, all the seedlings were transferred into 5-by-8 plastic seedling trays and cultured in a walk-in-chamber under $25 / 25^{\circ} \mathrm{C}$ with a $16 \mathrm{~h}$ photoperiod at Seoul National University (SNU).

For the inheritance study of resistance to PVX, three $\mathrm{F}_{2}$ segregating populations were used. Crosses were made between the $C$. annuum genotypes Perrenial (Per) and Dempsey (Demp); CV3 and Jeju and their $\mathrm{F}_{2}$ progenies were developed. C. annuum cv. 'Bukang' is a commercial $\mathrm{F}_{1}$ cultivar; self-pollinated progenies of Bukang were used as the third $F_{2}$ population.

PVX isolates and disease screening. Two PVX strains, UK3 and USA, were used in this study. UK3 is one of the typical strains in group 3 which was originally found in Europe (Kavanagh et al., 1992) and provided by Dr. David Baulcombe. USA strain (Hemenway et al., 1988), a field isolate in Washington State USA, was provided kindly from Dr. Kook-Hyung Kim of SNU and the grouping has not been yet classified (Hemenway et al., 1990). Both strains were propagated in young Nicotian benthamiana plants. Virus inoculum was prepared by grinding $1 \mathrm{~g}$ of young leaves of infected $N$. benthamiana in $10 \mathrm{ml}$ of inoculation solution (0.1 M potassium phosphate buffer, $\mathrm{pH}$ 7.0).

To investigate plant response to PVX, the third- and fourth-oldest leaves of 5-week-old seedlings (at the 4 to 6 true leaf stage) were mechanically inoculated with the two PVX strains. Symptom development was monitored up to eight weeks and ELISA test was performed to determine PVX accumulation.

DAS-ELISA test. Plants were assessed by DAS-ELISA according to the manufacturer's instructions using a commercial monoclonal antibody (Agdia, USA). ELISA substrate-enzyme reactions were read one hour later using a ELISA reader (Zenyth 340RT, Rose scientific Ltd., Austria) at $405 \mathrm{~nm}$. For DAS-ELISA analysis, two leaf discs of the inoculated leaves were sampled one week after inoculation and uninoculated leaves were sampled two weeks after inoculation. For genetic analysis, uninoculated leaves were sampled four weeks after inoculation.

Statistical analysis. The goodness of fit between ratios of resistant: susceptible plants with genetic hypothesis were tested using $\chi^{2}$ test. $\mathrm{P}$ value calculation was performed (http://www.graphpad.com/quickcalcs/pvalue1.cfm).

\section{Results}

Response of $\boldsymbol{C}$. annuum genotypes to PVX strains. To identify PVX resistant plants, eleven $C$. annuum genotypes, including one Korean commercial cultivar, two Korean local varieties and eight genotypes, were tested for resistance against two PVX strains, UK3 and USA. Among them, eight genotypes confer resistance to important pepper viruses (Table 1). Whereas Chil, ECW and Jeju have shown susceptibility to most viruses.

Table 1. Plant materials used in this study

\begin{tabular}{|c|c|c|c|}
\hline Genotype & Species & Origin of material & Known virus resistance \\
\hline CV3 & C. аппиит & $\mathrm{AVRDC}^{\mathrm{c}}$ & CVMV \\
\hline CV4 & C. аппиит & AVRDC & CVMV \\
\hline CV8 & C. аппиит & AVRDC & CVMV \\
\hline CV9 & C. аппиит & AVRDC & CVMV \\
\hline Perennial (Per) & C. annuиm & AVRDC & CMV, Potyviruses \\
\hline Bukang & C. аппиит & Seminis Korea & CMV, TMV \\
\hline CM334 (CM) & C. аппиит & INRA $^{\mathrm{d}}$, France & Potyviruses \\
\hline Dempsey (Demp) & C. annuum & Cornell University & Potyviruses \\
\hline Chilsungcho (Chil) & C. апnиum & Korean local variety & - \\
\hline Early Calwonder (ECW) & C. апnиит & Cornell University & - \\
\hline Jeju & C. аппиит & Korean local variety & - \\
\hline
\end{tabular}

Note: ${ }^{a} \mathrm{~S}=$ susceptible, ${ }^{b} \mathrm{R}=$ resistant, ${ }^{\mathrm{c}} \mathrm{AVRDC}$, Asia Vegetable Research and Development Center, ${ }^{\mathrm{d}} \mathrm{INRA}=$ Institute National de la Recherche Agronomique 
A

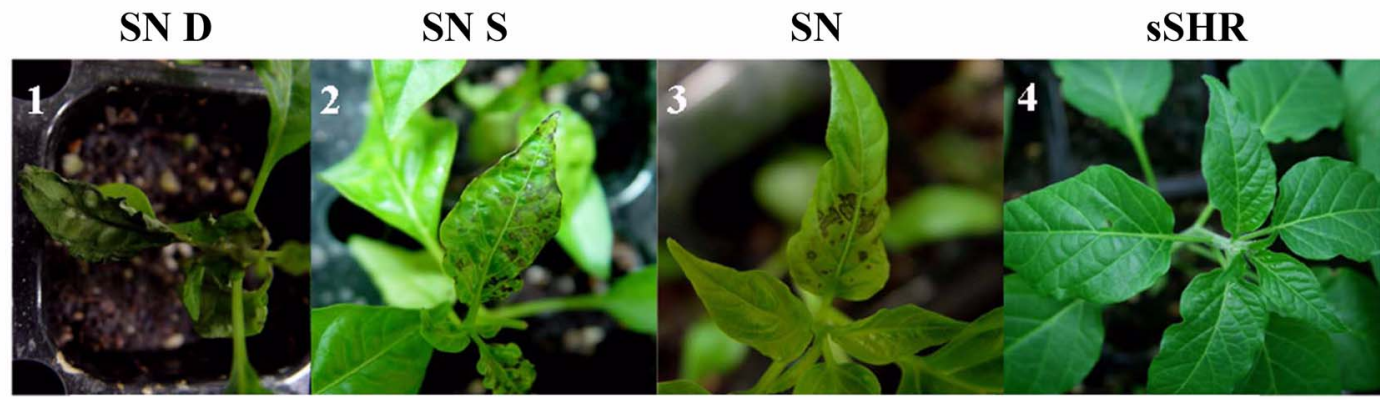

B

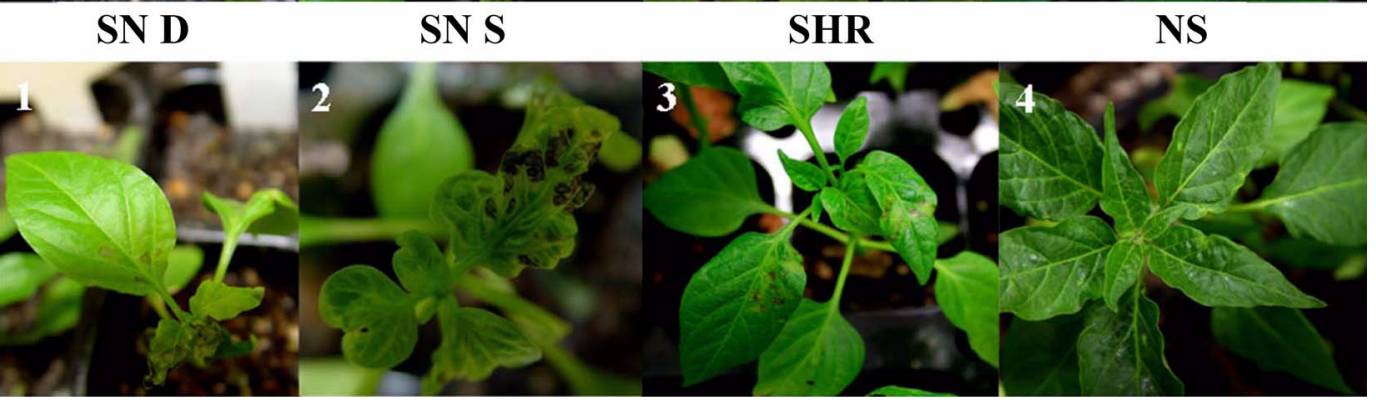

Fig. 1. Plant responses induced upon infection with PVX-UK3 (A) and PVX-USA (B) strains. The pictures show typical responses observed in this study. In panel A: Jeju (1); CV8 (2); Bukang (3) and CM (4). In panel B: CV4 (1); ECW (2); Per (3) and CM (4). SN, $\mathrm{D}=$ severe necrosis and death; $\mathrm{SN}, \mathrm{S}=$ severe necrosis and stunting; $\mathrm{SN}=$ severe necrosis; $\mathrm{SSHR}=$ sporadic systemic hypersensitive response; $\mathrm{SHR}=$ systemic hypersensitive response; $\mathrm{NS}=$ no symptom.

For USA strain, four genotypes, Bukang, CV3, CM and Per, showed resistant response, while the other 7 genotypes showed susceptible response (Fig. 1). For the susceptible genotypes, severe necrotic symptom was developed 5 days post inoculation (dpi) on inoculated leaves, and systemic symptoms including severe necrosis, stunting and death started to develop on systemic leaves $10 \mathrm{dpi}$. Susceptible genotypes could be grouped into two types base on the observed symptoms (Table 2). As for genotypes of CV4, CV9, Demp and Jeju, severe systemic necrosis was observed on systemic leaves as virus spread, then plant development stopped and infected plants eventually were killed. For genotypes such as CV8, ECW and Chil, systemic necrosis symptom was also observed and infected plants became severely stunted but no plant death occurred (Fig. 1A). Bukang, CV3 and Per developed the typical resistant

Table 2. Summary of plant responses to PVX strains

\begin{tabular}{lcccccccc}
\hline \hline \multirow{2}{*}{ Accession } & \multicolumn{4}{c}{ UK3 strain } & \multicolumn{3}{c}{ USA strain } \\
\cline { 2 - 9 } & \multicolumn{2}{c}{ Inoculated leaves } & \multicolumn{2}{c}{ Systemic leaves } & \multicolumn{2}{c}{ Inoculated leaves } & \multicolumn{2}{c}{ Systemic leaves } \\
\cline { 2 - 9 } & Response & ELISA & Response & ELISA & Response & ELISA & Response & ELISA \\
\hline CV3 & SN & High & SN, S & High & LN & High & SHR & Low \\
CV4 & SN & High & SN, S & High & SN & High & SN, D & Low \\
CV8 & SN & High & SN, S & High & SN & High & SN, S & High \\
CV9 & SN & Medium & SN, D & Medium & SN & High & SN, D & High \\
Per & SN & Medium & SN & Medium & LN & Medium & SHR & Low \\
Bukang & SN & High & SN & Medium & LN & High & SHR & Low \\
CM & LN & High & SSHR & High & LN & High & NS & Low \\
Demp & SN & High & SN, D & High & SN & High & SN, D & High \\
Chil & SN & High & SN, D & High & SN & High & SN, S & Medium \\
ECW & SN & High & SN, S & High & SN & High & SN, S & High \\
Jeju & SN & Low & SN, D & Medium & SN & Medium & SN, D & Medium \\
\hline
\end{tabular}

Note: SN, severe necrosis; LN, local necrosis; S, severe necrosis and stunting; D, severe necrosis and death; sSHR, sporadic systemic hypersensitive response; SHR, systemic hypersensitive response; NS, no symptom. 

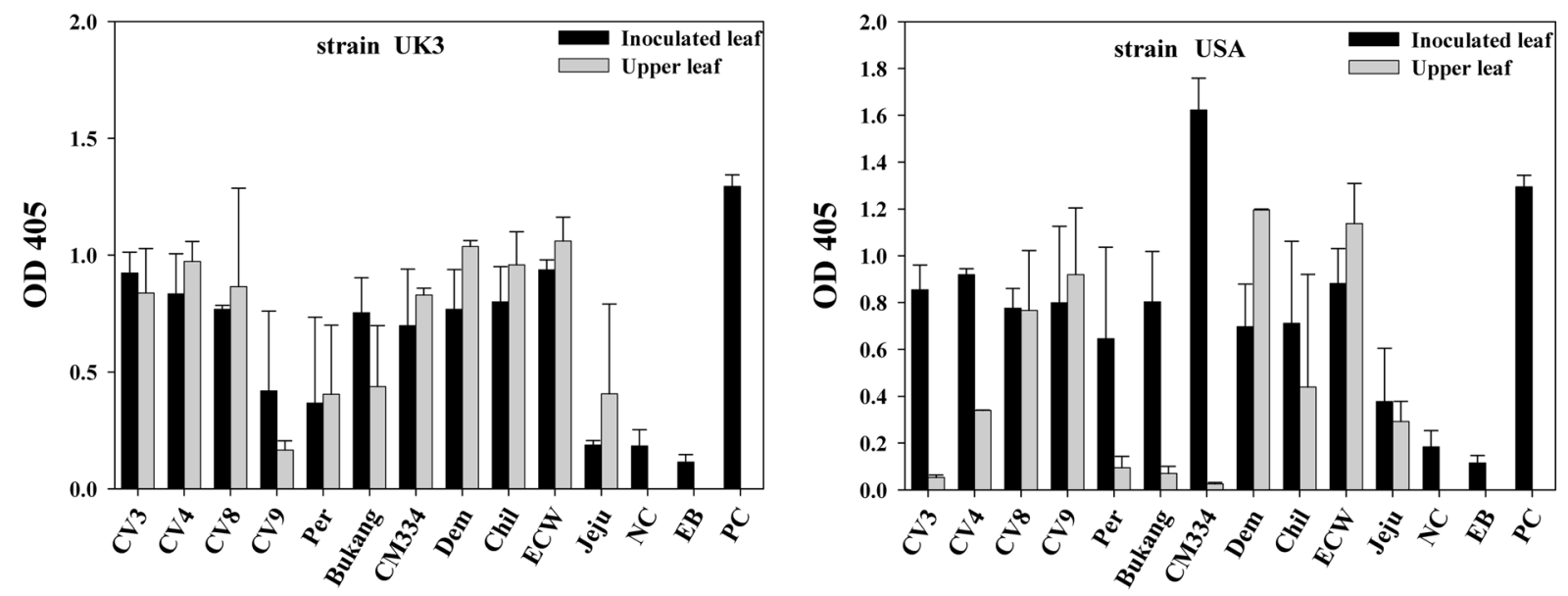

Fig. 2. DAS-ELISA analysis results of 11 pepper genotypes. Inoculated $N$. benthamiana leaves were taken as positive control (PC) and uninoculated $N$. benthamiana leaves and extraction buffer (EB) were used as negative control (NC). A single standard deviation is represented by the line above each bar. Except for CV4 and Demp, more than 3 plants for each genotype were used for the ELISA test.

response, local necrosis, on the inoculated leaves on 5 dpi and some of these plants showed systemic HR in uninoculated systemic leaves. In contrast CM only developed point necrosis or symptomlessness up to 56 dpi (Fig. 1A).

For strain UK3, all the screened genotypes showed susceptible responses (Fig. 1). The susceptible symptom development speed was similar to strain USA but four different types of susceptible response were observed. Genotypes of CV9, Demp, Chil and Jeju showed very high susceptibility and the infected plants died very quickly. Genotypes, such as Per and Bukang, developed severe necrosis on both inoculated and systemic leaves, while CV3, CV4, CV8 and ECW showed similar symptoms and stunting was accompanied. CM also developed necrotic symptoms but the development was slower and milder than other genotypes. Local necrosis on the inoculated leaves and sporadic systemic HR on systemic leaves were observed but stunting symptom was never observed in CM.

In order to confirm the observed plant responses, DASELISA analysis was performed (Fig. 2). For strain USA, PVX-CP accumulations of CV3, Per, Bukang and CM in the inoculated systemic leaves were very high while very low CP accumulation was detected from the upper systemic leaves compared with the negative control.

For the susceptible genotypes, although the ELISA values in systemic leaves varied among genotypes, most of them were obviously higher than negative control. In the case of Jeju, very high susceptibility of the plant caused death of the inoculated and systemic leaves, as a result low ELISA absorbance was detected. The low ELISA value of upper leaves in CV4 was also the result of plant death. As for Chil, upper leaves of some plants stopped developing and remained very small, therefore inconsistent sample amount enlarged the standard deviation. For strain UK3, all the genotypes were positive in ELISA test. Also the high susceptibility of CV9 and Jeju lead to the relatively low ELISA values.

In general, DAS-ELISA analysis results were consistent with observed plant responses.

Genetic analyses. To study inheritance of the resistance to PVX-USA strain in $C$. annuum, three $\mathrm{F}_{2}$ populations derived from resistant parent CV3, Bukang and Per were used (Table 3). All $F_{2}$ populations were examined for symptom development up to 8 weeks post inoculation (wpi) and DAS-ELISA was performed to confirm the phenotype results at $28 \mathrm{dpi}$.

In all the three $F_{2}$ segregating populations, three types of responses were observed: local necrosis, systemic HR and severe systemic necrosis. ELISA test results showed that plants showing local necrosis and systemic HR did not accumulate PVX CP in the systemic leaves while plants showing systemic necrosis allowed high $\mathrm{CP}$ accumulation in the upper young leaves. Therefore the local necrosis and

Table 3. Segregation of resistance and susceptibility to PVX in $\mathrm{F}_{2}$ populations examined by ELISA

\begin{tabular}{lccccc}
\hline \hline \multirow{2}{*}{ Parents/populations } & \multicolumn{3}{c}{ No. of plants } & \multicolumn{3}{c}{ Chi-square } \\
\cline { 2 - 6 } & $\mathrm{R}$ & $\mathrm{S}$ & Model & $\chi^{2}$ & P-value \\
\hline $\mathrm{CV} 3$ & 5 & 0 & & & \\
Jeju & 0 & 10 & & & \\
$\left(\mathrm{CV} 3 \times\right.$ Jeju) $\mathrm{F}_{2}$ & 48 & 50 & $9: 7$ & 2.065 & 0.1507 \\
Per & 9 & 0 & & & \\
Demp & 0 & 6 & & & \\
$\left(\right.$ Per $\times$ Demp) $\mathrm{F}_{2}$ & 107 & 7 & $15: 1$ & 0.023 & 0.8795 \\
Bukang & 10 & 0 & & & \\
Bukang $\mathrm{F}_{2}$ & 153 & 9 & $15: 1$ & 0.258 & 0.6115 \\
\hline
\end{tabular}


systemic HR were considered as resistant responses and systemic necrosis and plant death as susceptible responses.

The development of local necrosis and systemic necrosis were very similar among the three $\mathrm{F}_{2}$ populations whereas occurrences of systemic HR varied in different populations. Systemic HR mostly developed 2 wpi and continued to develop up to 4 wpi. Systemic HR was mostly developed in the leaves directly above the inoculated leaves, but in some cases two or three leaves above the inoculated leaves showed systemic necrosis and did not develop any further. Among the three $\mathrm{F}_{2}$ populations, the systemic HR symptom was most commonly observed in Bukang $\mathrm{F}_{2}$ population. In contrast, less than 5 plants showed systemic HR in CV3 $\mathrm{x}$ Jeju $\mathrm{F}_{2}$ segregation population.

Three $\mathrm{F}_{2}$ populations showed different segregation pattern for resistance and susceptibility. The goodness of fit for each gene model was tested using $\chi^{2}$ test and $\mathrm{P}$ values for the observed data were calculated. Screening of $\mathrm{F}_{2}$ progenies derived from $\mathrm{CV} 3 \times$ Jeju resulted in 48 resistant and 50 susceptible plants. The $\chi^{2}$ test for this $\mathrm{F}_{2}$ population showed a good fit $(P=0.15)$ to a 9R:7S model for two complementary dominant genes (Table 3 ). In the $\mathrm{F}_{2}$ population derived from Per $\times$ Demp, 107 plants were resistant and 7 plants were susceptible. The $\chi^{2}$ test for segregation of this $\mathrm{F}_{2}$ population showed a good fit $(P=0.87)$ to a $15 \mathrm{R}: 1 \mathrm{~S}$ model for two independent dominant genes (Table 3 ). The $\chi^{2}$ test for Bukang $\mathrm{F}_{2}$ data also supports two independent dominant gene model $(\mathrm{P}=0.61)$ which produced 153 resistant plants and 9 susceptible plants (Table 3).

\section{Discussion}

In this study, resistance of C.annuum genotypes against PVX strains has been examined. The results showed that four genotypes, Bukang, CM, CV3 and Per, confer resistance to USA strain and none was resistant to UK3. Although we were able to identify several resistant genotypes, such a small number of resistant genotypes were unexpected because PVX has not been considered as a serious virus in pepper production. However, to our surprise, two thirds of genotypes were susceptible to USA strain and no tested genotypes were resistant to strain UK3. Our results show that PVX could be a future threat for pepper production in Korea.

PVX strains have been classified into four virulence groups based on their ability to overcome the host reaction genes $N x, N b$, and $R x$ (Cockerham, 1954). PVX strain UK3 is one of the typical strains in group 3 which was originally found in Europe (Kavanagh et al., 1992), while USA strain was isolated in Washington State (Hemenway et al., 1988) and has not been yet classified (Hemenway et al., 1990). In our study, strains UK3 and USA showed different virulence to pepper genotypes that UK3 was virulent to all tested pepper genotypes whereas USA was avirulent to four genotypes. The distinct response may be explained by the different origins of USA and UK3 strains. Two of three isolated Korean PVX strains (KO1 and KO2) were identified as the type $\mathrm{X}$ which overcomes the $N x$ gene, and the KR strain also showed very high sequence similarity with $\mathrm{KO} 1$ and $\mathrm{KO} 2$ strains. This indicates that all the Korean isolates may be the same group as strain UK3 to which none of the screened $C$. annuum genotypes were resistant. In order to test whether Korean isolates have the same virulence as strain UK, resistant genotypes identified in this study should be rescreened.

The resistance responses in potato and pepper were different. In potato, there are two types of resistance response: extreme resistance and hypersensitive response. ER can lead to no detectable symptom or very less necrosis and rapid arrest of PVX accumulation in the initially infected cell. For hypersensitive response, lesion or local necrosis can be induced in inoculated leaves upon virus inoculation, while systemic HR can be induced by the $N x$ gene on high inoculum concentrations or graft-inoculation (Kavanagh et al., 1992). In pepper, immune-like response was also observed in CM while the virus accumulation was detected on the inoculated leaves (Fig. 2), which is different from the extreme resistance in potato. Local necrosis and systemic HR were observed in all the identified resistant genotypes. In our study, some plants of a same genotype showed HR and others showed systemic HR when plants were inoculated in the same environment conditions. This suggests that the concentrations of inoculum may be responsible for the HR or systemic HR because the concentrations of inoculum were very difficult to control in each experiment. This should be confirmed by further study.

The inheritance of resistance to PVX in pepper seems to be more complex than that of potato. The inheritance studies of $\mathrm{F}_{2}$ populations suggested that Bukang and Per contained two unlinked dominant genes. These results were confirmed by ELISA analysis. The ELISA data showed that the resistance genes in Bukang and Per suppress systemic movement of PVX. The resistance in CV3 appeared to be controlled by two complementary dominant genes. Such inheritance patterns have not been reported for PVX resistance in potato (Solomon et al., 2001). This may be due to difficulty in manipulating resistance genes with a complex inheritance pattern in a breeding procedure (Hemenway et al., 1990; Hemenway et al., 1988). In order to make use of dominant resistant genes in Per and Bukang, $\mathrm{F}_{3}$ progeny test should be done to identify $\mathrm{F}_{2}$ individuals containing one dominant resistant gene and the selected $\mathrm{F}_{2}$ plants can be used as resistance sources for breeding PVX resistance cultivars. However, resistance in CV3 will be 
more difficult to use in breeding.

In conclusion, to our knowledge this is the first report about the genetic analysis of PVX resistance in pepper. Our result showed that developing PVX resistant cultivars is necessary and C. annuum Per, CV3 and CM can be used as suitable resistance sources, especially CM because of the symptomless response to PVX. Further effort of mapping and identifying molecular markers linked to the resistance genes will expedite developing a PVX resistant pepper cultivar.

\section{Acknowledgement}

This work was supported by a grant (20070401034028) from BioGreen 21 Program, Rural Development Administration, Republic of Korea. We thank Dr. Kook-Hyung Kim for providing PVX USA strain and W. Liu for critical review of this manuscript.

\section{References}

Abe, K. and Kotobuki, K. 1998. Polygenic inheritance of necrotic reaction to pear scab (Venturia nashicola Tanaka et Yamamoto) in Japanese pear (Pyrus pyrifolia Nakai) and Chinese pear (P. ussuriensis Maxim.). J. Japan Soc. Hort. Sci. 67:839642.

Bendahmane, A., Kanyuka, K. and Baulcombe, D. C. 1997. High-resolution genetical and physical mapping of the $R x$ gene for extreme resistance to potato virus $\mathrm{X}$ in tetraploid potato. Theor. Appl. Genet. 95:153-162.

Bendahmane, A., Kanyuka, K. and Baulcombe, D. C. 1999. The $R x$ gene from potato controls separate virus resistance and cell death responses. Plant Cell 11:781-792.

Brown, C. R. and Thomas, P. E. 1994. Resistance to potato leafroll virus derived from Solanum chacoense: characterization and inheritance. Euphytica 74:51-57.

Cockerham, G. 1954. Strains of potato virus X. Pages 89-92 in: Proc Conf. Potato Virus Diseases, $2^{\text {nd }}$.

Cockerham, G. 1970. Genetical studies on resistance to potato virus $\mathrm{X}$ and Y. Heredity 25:309-348.

Fisher, M. L. and Kyle, M. M. 1996. Inheritance of resistance to potyviruses in Phaseolus vulgaris L. 4. Inheritance, linkage relations, and environmental effects on systemic resistance to four potyviruses. Theol. Appl. Genet. 92:204-212.

Green, S. K. and Kim, J. S. 1994. Sources of resistance to viruses of pepper (Capsicum spp.): a catalog. Pages 29-31 in Asian Vegetable Research and Development Center. Technical Bulletion No. 20.

Hemenway, C., Fand, R. X., Kaniewski, W. K., Chua, N. H. and Tumer, N. E. 1988. Analysis of the mechanism of protection in transgenic plants expressing the potato virus $\mathrm{X}$ coat protein or its antisense RNA. EMBO J. 7:1273-1280.
Hemenway, C., Weiss, J., O'Connel, K. and Tumer, N. E. 1990. Characterization of infectious transcripts from a potato virus $\mathrm{X}$ cDNA clone. Virolog 175:365-371.

Hughes, S. L., Green, S. K., Lydiate, D. J. and Walsh, J. A. 2002. Resistance to turnip mosaic virus in Brasica rapa and $B$. napus and the analysis of gentic inheritance in selected lines. Plant Pathology 51:567-573.

John, R. E. and Richard, G. C. 1997. Viruses infecting peppers and other solanaceous crops; v.2 Agricultural Experiment Station, University of Florida.

Jung, H. W., Yun, W. S., Seo, H. W., Hahm, Y. I. and Kim, K. H. 2000. Characterization and partial nucleotide sequence of Potato virus $X$ isolated from potato in Korea. Plant Pathol. J. 16:110-117.

Kavanagh, T., Goulden, M., Santa Cruz, S., Chapman, S., Barker, I. and Baulcombe, D. C. 1992. Molecular analysis of a resistance-breaking strain of potato virus X. Virology 189:609-617.

Kohm, B. A., Goulden, M. G., Gilbert, J. E., Kavanagh, T. A. and Baulcombe, D. C. 1993. A Potato Virus X resistance gene mediates an induced, nonspecific resistance in protoplasts. Plant Cell. 5:913-920.

Malcuit, I., Marano, M. R., Kavanaugh, T., De Jong, W., Forsyth, A. and Baulcombe, D. C. 1999. The 25-kDa movement protein of PVX elicits Nb-mediated hypersensitive cell death in potato. Mol. Plant-Microbe Interact. 12:536-543.

Marano, M. R., Malcuit, I., De Jong, W. and Baulcombe, D. C. 2002. High-resolution genetic map of $N b$, a gene that confers hypersensitive resistance to potato virus X in Solanum tuberosum. Theor. Appl. Genet. 105:192-200.

Markham, R. 1977. Landmarks in plant virology: genesis of concepts. Annual Review of Phytopathology 15:17-39.

Moffett, P., Farnham, G., Peart, J. and Baulcombe, D. C. 2002. Constitutive gain-of-function mutants in a nucleotide binding site-leucine rich repeat protein encoded at the $R x$ locus of potato. The Plant Journal 32:195-204.

Park, S. H. and Kim, K. H. 2006. Agroinfiltration-based potato virus $\mathrm{X}$ replications to dessect the requirements of viral infection. Plant Pathol. J. 22:386-390.

Ritter, E., Debener, T., Barone, A., Salamini, F. and Gebhardt, C. 1991. RFLP mapping on potato chromosomes of two genes controlling extreme resistance to potato virus X (PVX). Mol. Gen. Genet. 227:81-85.

Santa Cruz, S. and Baulcombe, D. C. 1995. Analysis of potato virus $\mathrm{X}$ coat protein genes in relation to resistance conferred by the genes $N x, N b$ and $R x l$ of potato. J. Gen. Virol.76:20572061.

Solomon-Blackburn, R. M. and Barker, H. 2001. A review of host major-gene resistance to potato viruses $\mathrm{X}, \mathrm{Y}, \mathrm{A}$ and $\mathrm{V}$ in potato: genes, genetics and mapped locations. Heredity 86:816.

Tommiska, T. J., Hämäläinen, J. H., Watanabe, K. N. and Valkonen, J. P. T. 1998. Mapping of the gene $N x_{p h u}$ that controls hypersensitive resistance to potato virus $\mathrm{X}$ in Solanum phureja InP35. Theor. Appl. Genet. 96:840-843. 